\title{
Análise das dificuldades na aprendizagem de programação no curso de análise e desenvolvimento de sistemas do IFRN/Pau dos Ferros
}

\author{
Francisco Leocassio da Silva, Irlan Arley Targino Moreira ${ }^{2}$ \\ ${ }_{1,2}$ Curso Superior em Tecnologia em Análise e Desenvolvimento de Sistemas - \\ IFRN/Campus de Pau dos Ferros - Pau dos Ferros - RN - Brazil \\ \{leocassiosilva1234@gmail.com, Irlan.moreira@escolar.ifrn.edu.br\}
}

\begin{abstract}
This study presents as realities and particularities, which can contribute to the high rate of failures and / or dropout of students in the programming disciplines, of the Systems Analysis and Development Course (SAD), from the Federal Institute of Education, Science and Technology of the Rio Grande do Norte - IFRN, Pau dos Ferros campus. For the construction of the data, a bibliographic research bulletin is used, which is consistent with some studies already carried out in this area of knowledge. Subsequently, exploratory research was used, combined with a structured questionnaire, which had as respondents students from the aforementioned course. It was found that among the difficulties mentioned by the students, the difficulty in putting into practice that they study in the theoretical part, the abstraction of the problems and the logical reasoning stand out. In view of this reality, it is concluded that these problems can culminate in student demotivation, failure and school dropout.
\end{abstract}

Resumo. Considerando que as disciplinas de programação são a base dos cursos de computação, este estudo apresenta as realidades e particularidades que podem contribuir para os altos indices de reprovações elou evasões de estudantes nas disciplinas de programação do Curso de Análise e Desenvolvimento de Sistemas ADS, do Instituto Federal de Educação, Ciência e Tecnologia do Rio Grande do Norte - IFRN, Campus Pau dos Ferros. Para a construção dos dados, utilizou-se inicialmente a pesquisa bibliográfica, a qual permitiu levantar alguns estudos já realizados nesta área do conhecimento. Posteriormente, fez-se uso da pesquisa exploratória combinada com um questionário estruturado, o qual teve como respondentes estudantes do curso supracitado. Verificou-se que entre as dificuldades citadas pelos estudantes, destacam-se a dificuldade em colocar em prática o que estudam na parte teórica, a abstração dos problemas e o raciocínio lógico. Em face dessa realidade, conclui-se que esses problemas podem culminar na desmotivação, reprovação e evasão escolar desses estudantes.

\section{Introdução}

Ao analisar a grade curricular dos cursos na área da computação é possível perceber que as disciplinas de algoritmo e programação constituem as suas bases, sejam eles tecnólogos, bacharelados ou licenciaturas. Isso faz com que os discentes tenham contato com estes componentes curriculares logo em seu primeiro ano de trajetória acadêmica. Neste sentido, para Bosse e Gerosa (2015), entender e aplicar os conceitos estudados nas disciplinas de introdução à programação é fundamental para que o aluno consiga se desenvolver em programação de sistemas mais avançados. 
Entretanto, convém salientar que o estudo dessas disciplinas é uma tarefa complexa, pois requer dos estudantes compreensão de problemas, raciocínio lógico e outros conhecimentos matemáticos. Logo, esses aspectos podem contribuir para os altos índices de reprovações. Na concepção de Santos e Costa (2006), as reprovações em algoritmo e programação e até mesmo a desistência dos cursos pelos estudantes, podem acontecer porque estes não conseguem entender conceitos básicos/introdutórios dessas disciplinas como por exemplo acontece com raciocínio lógico.

Ademais, os estudantes podem utilizar métodos inadequados para solucionar problemas/algoritmos. Um exemplo seria quando o aluno recorre a internet e/ou a um colega para buscar resposta pronta para um referido problema. Assim, ele acaba por não exercitar o raciocínio e a lógica de programação, o que tende a comprometer o seu conhecimento.

Gomes, Henriques e Mendes (2008), afirmam que em relação aos métodos adotados pelos estudantes, estes se mantêm acostumados com disciplinas nas quais sua prática acontece por meio de leituras, memorização de fórmulas e mecanização de procedimentos. Deste modo, é necessário que os estudantes mudem as estratégias de estudo, para que possam alcançar bons resultados nas disciplinas de programação.

Nesse contexto, o presente estudo teve como objetivo conhecer a realidade e particularidade dos estudantes do Curso de Análise e Desenvolvimento de Sistemas ADS, no Instituto Federal de Educação, Ciência e Tecnologia do Rio Grande do Norte IFRN, Campus Pau dos Ferros, em relação às principais dificuldades nas disciplinas de algoritmos/programação, as quais, segundo a hipótese desse estudo, podem contribuir para o alto índice de reprovação e/ou evasão nos cursos da área da computação.

A escolha pela temática de pesquisa justifica-se por causa dos altos índices de reprovação e evasão dos estudantes no curso de ADS do IFRN, campus Pau dos Ferros. Além disso, busca contribuir para com a instituição de ensino, com o curso, com coordenador e seus docentes, em relação aos principais problemas e desafios encontrados pelos estudantes, para que com isso os responsáveis possam tomar medidas para minimização desses índices.

\section{Trabalhos Relacionados}

No seu trabalho, Vieira, Lima Junior e Vieira (2015) buscaram identificar quais as principais dificuldades no processo de aprendizagem de algoritmos e como estas corroboram para o índice de reprovação ser superior ao índice de aprovação nessa disciplina, no curso de sistema de informação da Faculdade de Educação Tecnológica do Estado Rio de Janeiro - FAETERJ, Campus Paracambi. A pesquisa apontou problemas na parte de raciocínio lógico, estrutura de repetição, estrutura de dados homogêneas, matrizes e vetores. Um ponto que pode contribuir para essas dificuldades é o fato dos alunos não disporem de conhecimento sobre lógica ou algoritmos, porque, em sua maioria, são advindos do ensino médio regular.

Em seu estudo, Medeiros (2019) buscou compreender melhor os problemas e desafios tanto no ensino como na aprendizagem de disciplinas de introdução à programação em nível superior, a fim de proporcionar para outros pesquisadores do tema métodos de ensino e ferramentas educacionais mais eficientes e, deste modo, reduzir as dificuldades e evasão. Para isso, foi realizada uma revisão sistemática da literatura internacional, outra nacional e, por último, uma pesquisa com professores universitários dos cursos de STEM em universidades brasileiras. Nesse sentido, com as duas revisões foi possível identificar e categorizar os problemas. Por outro lado, o terceiro estudo buscou confrontar as respostas dos docentes com o que foi encontrado na literatura. 
Em sua pesquisa, Bosse (2020) procurou identificar padrões relacionados às dificuldades enfrentadas pelos discentes durante o aprendizado em disciplinas de introdução à programação. Para isso, utilizou-se de distintos métodos de pesquisa, podese citar entrevistas, diários, questionários, análises quantitativas e qualitativas. Dessa forma, os principais resultados obtidos foram a descoberta de um conjunto de dificuldades por conteúdo (variáveis, estrutura de repetição e funções), uma lista de estratégias utilizadas pelos docentes, a relação destas com os problemas e um cenário do ensino de programação em uma universidade.

Pela observação dos aspectos analisados, percebe-se que são muitas as causas que culminam em problemas no processo de ensino-aprendizagem de disciplinas de programação e/ou áreas afins. Esses obstáculos podem aparecer para os docentes e, em especial, para os discentes. Para Santos (2006), uma possibilidade de solução que amenize esses problemas é a elaboração de produtos tecnológicos que facilitem e tragam novas experiências para ensino e aprendizagem de programação.

\section{Metodologia}

Esta pesquisa caracteriza-se por ser de abordagem mista, onde foram empregadas abordagens descritiva e qualitativa. Para Zanella (2013), a abordagem descritiva tem como propósito conhecer a realidade estudada, suas características e seus problemas. Por outro lado, a qualitativa refere-se às informações expressas em palavras orais e escritas.

O percurso metodológico para o desenvolvimento deste estudo está fundamentado inicialmente em pesquisa bibliográfica, com o propósito de verificar na literatura obras relacionadas ao tema, utilizando mecanismos de buscas como o Google Acadêmico. Deste modo, ressalta-se que a pesquisa bibliográfica é de suma importância para que o pesquisador tenha conhecimento sobre o que vem sendo pesquisado e produzido na referida área. Para Gil (2018, p.28), a pesquisa bibliográfica é "aquela em que se apoio de materiais já publicado, desde material impresso como livros, revistas, teses, dissertações e anais de eventos científicos, como de material disponibilizado na internet".

Na segunda etapa do trabalho foi desenvolvida uma pesquisa exploratória, através da aplicação de um questionário estruturado com questões abertas e fechadas, o qual teve como propósito investigar quais as principais dificuldades encontradas pelos estudantes do Curso de Análise e Desenvolvimento de Sistema - ADS nas disciplinas de algoritmo e programação, do Instituto Federal de Educação, Ciência e Tecnologia do Rio Grande do Norte - IFRN. O questionário foi elaborado através do Google Forms e compartilhado através de um link respondido por 25 dos 64 estudantes matriculados no semestre letivo 2020.1 , ou seja, participação efetiva de $39 \%$ dos estudantes. Ainda convém lembrar que o prazo para responder o questionário foi de 15/09/2020 a 05/12/2020, assim sendo, durante a pandemia causada pela covid-19. É importante ressaltar que durante este período o IFRN adotou a modalidade de ensino remoto, porém o curso normalmente é ofertado no formato presencial..

\section{Coleta e Análise dos dados}

Para a construção dos dados apresentados neste trabalho, fez-se necessário conhecer as principais dificuldades dos estudantes do Curso de ADS/IFRN campus Pau dos Ferros com as disciplinas de algoritmo e programação. Para isso, formulou-se um questionário com questões abertas e fechadas. 
Neste sentido, a primeira questão buscou identificar a faixa etária dos estudantes que colaboraram com a pesquisa, na qual destaca-se que entre os 25 respondentes, as idades variavam entre 19 e 25 anos. $68 \%$ dos estudantes analisados são do sexo masculino e $32 \%$ do sexo feminino. Constatou-se um perfil de estudantes jovens que integram o curso supracitado, com a predominância de homens.

Outro questionamento diz respeito à instituição de ensino em que os alunos cursaram o ensino médio, no qual identificou-se que $88 \%$ o cursaram integralmente em escolas públicas regulares, $16 \%$ em escolas técnicas e $4 \%$ em escolas privadas. Nessa questão, o aluno poderia marcar mais de uma opção.

Em relação ao período em que os discentes estão cursando, $32 \%$ estão no primeiro, $8 \%$ no segundo, $24 \%$ no terceiro, $8 \%$ no quarto, $24 \%$ no quinto, e $4 \%$ no sétimo. Como é um curso tecnológico, possui duranção de 3,5 anos, totalizando 7 períodos.

Posteriormente, buscou-se conhecer a jornada de trabalho semanal dos estudantes, onde $56 \%$ não trabalham, $20 \%$ afirmaram trabalhar de 10 a 20 horas, $16 \%$ mais de 40 horas e $8 \%$ de 21 a 40 horas. Perguntou-se também se os estudantes possuem computador (Desktop ou Notebook) em casa e obtive-se como resposta que $84 \%$ dispõem e $16 \%$ não. Procurou-se saber também onde os estudantes acessam a internet e ficou constatado que $88 \%$ acessam em casa, $28 \%$ no IFRN, $24 \%$ na casa de vizinhos/amigos, $8 \%$ no trabalho e $4 \%$ em praça ou parque de sua cidade. É importante frisar que nessa questão era possível marcar mais de uma resposta.

No que concerne às respostas da pergunta relacionada à reprovação nas disciplinas de programação, cálculo e lógica, do universo dos pesquisados, $52 \%$ afirmaram nunca ter reprovado, $28 \%$ disseram ter reprovado duas vezes, $16 \%$ uma vez e $4 \%$ quatro ou mais vezes.

Como pode ser observado, o número de alunos que nunca reprovaram em nenhuma das disciplinas supracitadas é superior ao número de reprovações, o que é bem satisfatório. No entanto, não se pode deixar de mencionar que o número de reprovações está bem próximo do número de sujeitos que nunca reprovaram, contabilizando um total de $49 \%$, variando na quantidade de repetência entre os estudantes.

Quanto ao Gráfico 1, este trata do tempo destinado diariamente pelos estudantes para dedicação aos assuntos relacionados à programação. Onde 32\% afirmou que se dedica menos de uma hora, $28 \%$ duas horas, $20 \%$ quatro horas ou mais, $16 \%$ uma hora e $4 \%$ três horas.

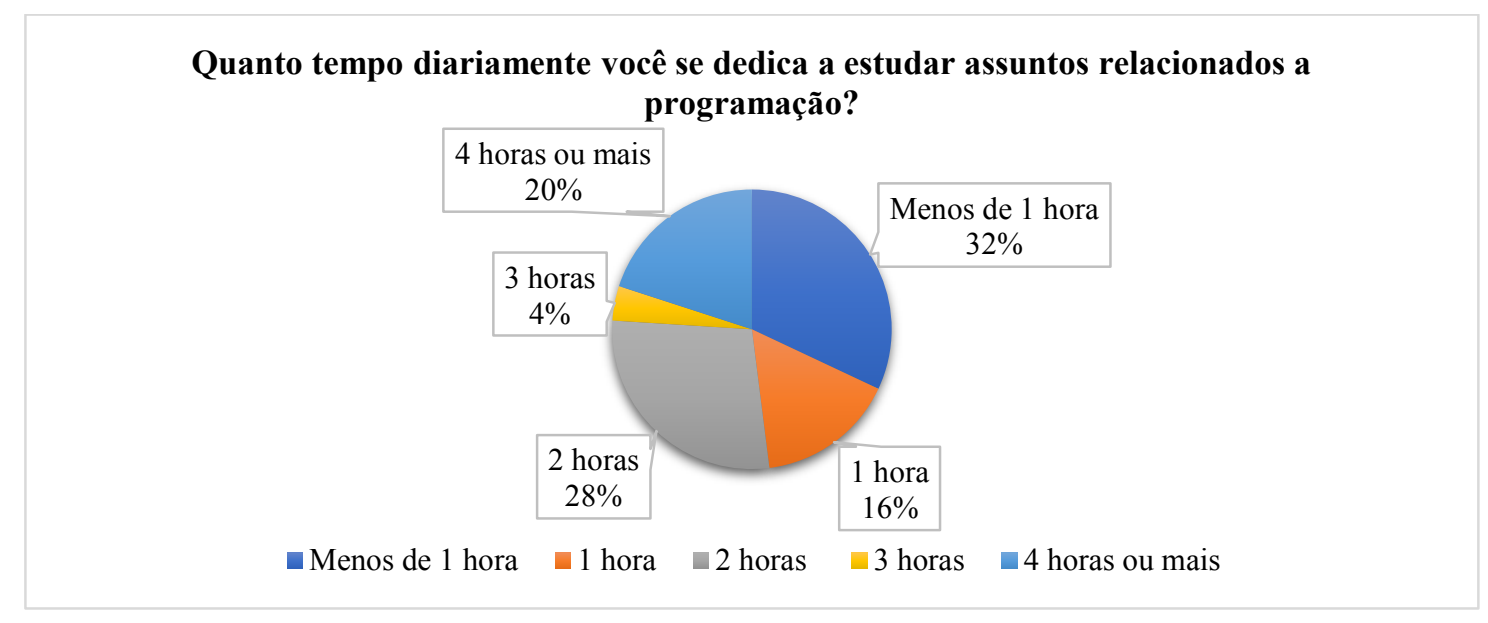

Gráfico 1. Tempo diariamente dedicado aos estudos.

Os assuntos relacionados à programação demandam estudo, motivação e disponibilidade para aprender, por isso é importante que os estudantes dediquem um 
tempo hábil para compreender os conteúdos e aplicá-los na resolução de problemas. $32 \%$ dos estudantes dedicam menos de uma hora semanal para os estudos de programação, o que se torna um dado preocupante, uma vez que esta disciplina exige conhecimentos práticos, que devem ser exercitados no decurso das disciplinas.

O Gráfico 2 diz respeito a como os estudantes resolvem os problemas (questões) de programação. $72 \%$ dos respondentes do questionário dizem primeiro compreender 0 que o problema trata e só depois desenvolvem a solução (código). 16\% desenvolve sem entender e $12 \%$ não compreende e não faz.

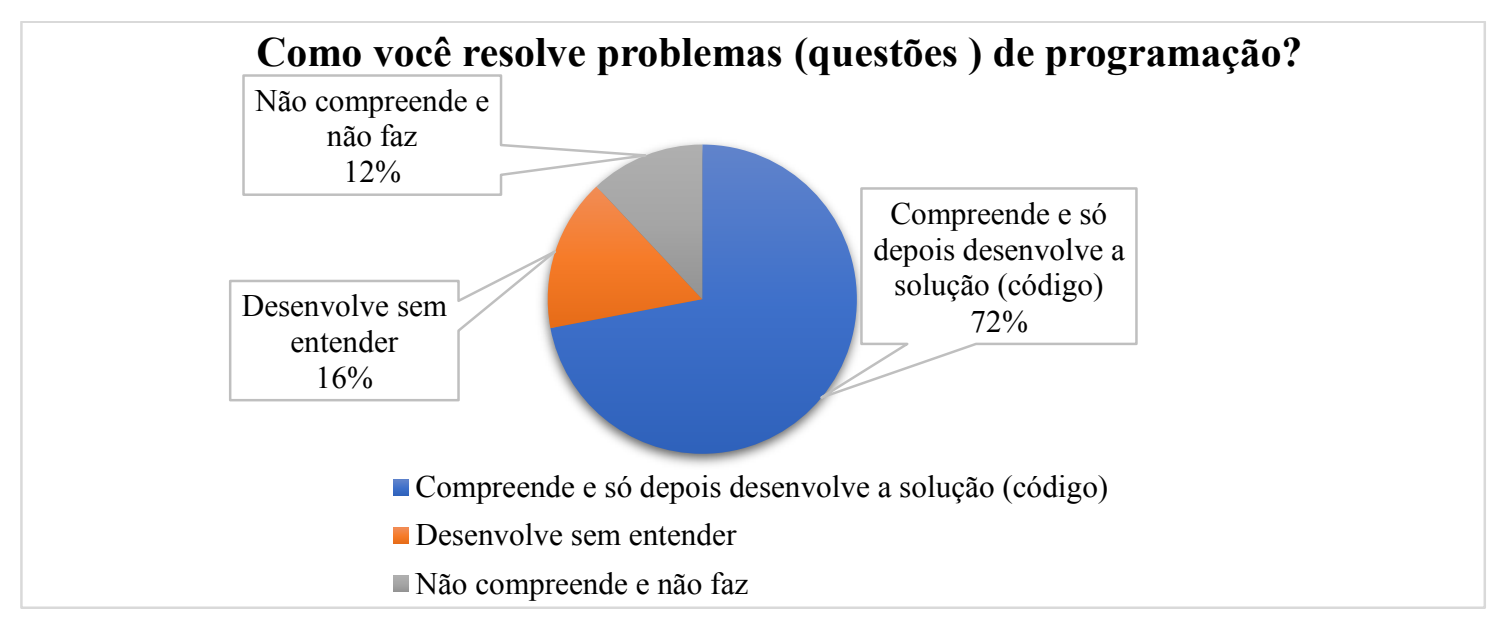

Gráfico 2. Como resolver problemas de programação.

Compreender o problema logo de início e quais conceitos e estratégias devem ser empregados para sua resolução pode fazer uma considerável diferença na resolução das questões problemas. Todavia, percebemos que apesar de $72 \%$ dos estudantes primeiro buscarem compreendê-las para poder desenvolver a solução, ainda há 16\% que desenvolvem sem entender, e outros que não o conseguem fazer, porque não entendem.

Outra questão levantada (Gráfico 3) foi em relação ao que os estudantes fazem quando não conseguem resolver o problema, onde 21 estudantes responderam que pesquisam por soluções na internet e/ou livros, 20 pedem ajuda para outros colegas, 16 pedem ajuda para professores e/ou monitores, e 2 abandonam o problema.

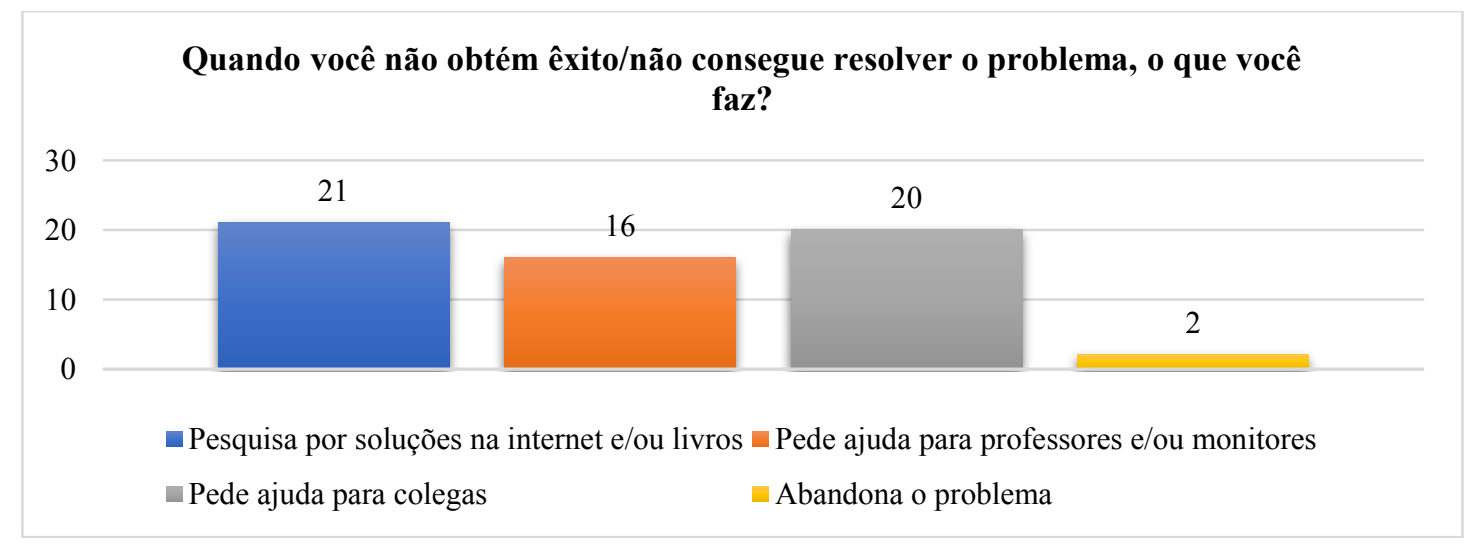

Gráfico 3. Quando não consegue resolver o problema.

Quando questionados sobre suas dificuldades nas disciplinas relacionadas à programação, o Gráfico 4 apresenta que 17 estudantes informaram que estas estão relacionadas com a dificuldade de colocar em prática o que aprendem na teoria, 4 afirmam que o problema está na compreensão da parte teórica e 6 não citam dificuldades. 


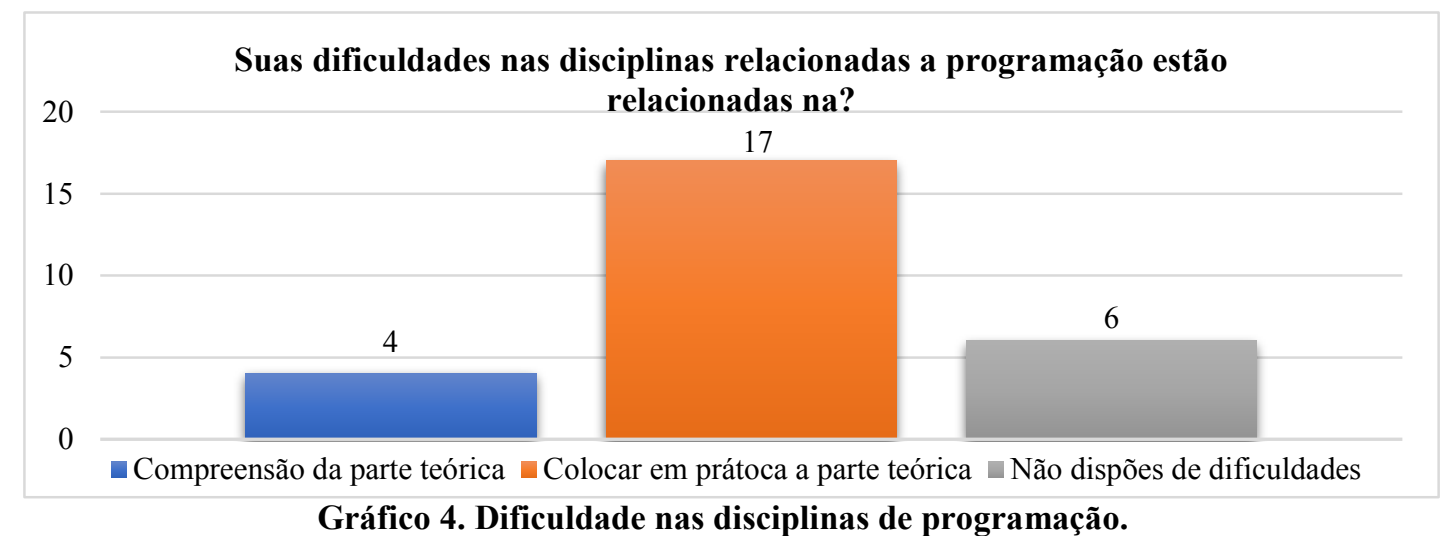

No que se refere às suas maiores dificuldades, 14 alunos destacam dificuldade na abstração do problema, 12 no raciocínio lógico, 6 na interpretação do texto e $5 \mathrm{em}$ aspectos matemáticos, conforme pode ser observado no Gráfico 6.

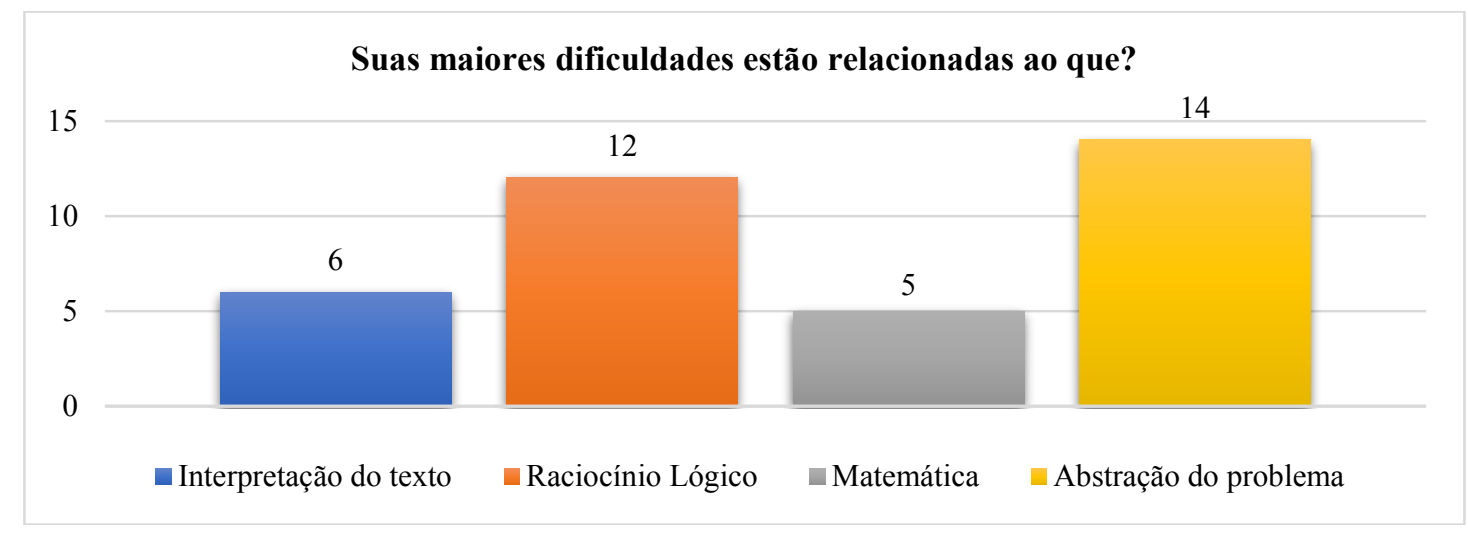

Gráfico 5. Maiores Dificuldades.

É possível perceber que tais problemas são passíveis de solução e podem ser sanados com esforço e dedicação dos alunos, bem como através de um enfoque e aperfeiçoamento da didática dos professores com base nas dificuldades elencadas.

Uma outra questão é se nas disciplinas de programação existia monitor $56 \%$, afirmaram a existência e 44\% a não existência. Quanto ao questionamento relacionado à didática dos docentes. 56\% considera boa, 28\% ótima, 12\% razoável e $4 \%$ ruim. Assim, observa-se que uma parcela dos estudantes afirma que a didática do docente é boa. Sobre a questão que procurou averiguar se a didática do docente é um contribuinte para as suas dificuldades nas disciplinas de programação, $68 \%$ dos estudantes acreditam que sim e $32 \%$ que não.

Procurou-se também identificar se o docente utiliza alguma ferramenta para melhorar o raciocínio dos estudantes e $64 \%$ declararam que sim e $36 \%$ que não. Outro questionamento foi feito no tocante ao acompanhamento da explicação dos docentes nas disciplinas de programação, onde $96 \%$ expressaram que conseguem acompanhar e $4 \%$ que não acompanham. Quanto à pergunta relacionada à disponibilização de tempo dos docentes para tirar dúvidas, $84 \%$ afirmaram que há a destinação desse tempo e 16\% disseram que não.

O Quadro 1 apresenta as recomendações de 13 dos estudantes que responderam o questionamento acerca de como melhorar a compreensão dos conteúdos de programação. 
Quais suas recomendações para melhorar a compreensão dos conteúdos de programação?

\begin{tabular}{|c|c|}
\hline Sujeitos & Respostas \\
\hline Estudante 1 & Pensar antes de agir. \\
\hline Estudante 2 & Compreender a lógica da programação. \\
\hline Estudante 3 & $\begin{array}{l}\text { Adaptar a forma de ensino ao conteúdo, para facilitar o aprendizado daqueles que têm } \\
\text { mais dificuldades. }\end{array}$ \\
\hline Estudante 4 & Praticar mais lógica e depois focar em sintaxes mais avançadas da linguagem. \\
\hline Estudante 5 & $\begin{array}{l}\text { Interesse por parte dos discentes. Pois, pelo que acompanho, a maioria das pessoas que } \\
\text { não entendem o assunto e que ficam reprovadas não tiram tempo algum para estudar. } \\
\text { Algumas até ficam nas aulas usando o celular e não dão atenção às explicações, depois } \\
\text { vão reclamar, dizer que é difícil e que não sabem. }\end{array}$ \\
\hline Estudante 6 & Ensinar os códigos e começar do mais fácil. \\
\hline Estudante 7 & $\begin{array}{l}\text { Fazer um sistema que englobe os conteúdos mais simples, e conforme for sendo } \\
\text { resolvidos os exercícios, ir mostrando como pode ser no dia a dia, fornecendo um } \\
\text { exemplo real. Além de incentivar a procura por conteúdos de diferentes fontes. }\end{array}$ \\
\hline Estudante 8 & $\begin{array}{l}\text { Alguns professores não atropelarem os conteúdos, já que tem alguns alunos que não tem } \\
\text { base nenhuma sobre programação! Tive um professor que explicava, mas não dava } \\
\text { tempo para os alunos absorverem o conteúdo. }\end{array}$ \\
\hline Estudante 9 & $\begin{array}{l}\text { O professor resolver um problema juntamente com os alunos e depois colocar um } \\
\text { semelhante para os alunos tentarem resolver sozinhos, colocando em prática o que } \\
\text { aprenderam. }\end{array}$ \\
\hline Estudante 10 & $\begin{array}{l}\text { Eu acredito que a explicação de uma maneira mais simples para o discente desenvolva } \\
\text { a solução. Ex: coisas do cotidiano. }\end{array}$ \\
\hline Estudante 11 & $\begin{array}{l}\text { Não avançar os conteúdos tão rápido, procurar uma maneira melhor para compreensão } \\
\text { dos alunos e ver se todos estão compreendendo o assunto antes de passar para o próximo. } \\
\text { Pois nem todos alunos só estudam, sem falar que tem outras disciplinas e outros afazeres } \\
\text { em casa. Além do mais, muitos alunos ao chegarem no curso não sabem programar e se } \\
\text { deparam com um universo novo. Pela falta de orientação ocorrem as desistências. }\end{array}$ \\
\hline Estudante 12 & $\begin{array}{l}\text { Professores menos rígidos e que deem uma explicação mais detalhada para que todos os } \\
\text { alunos entendam os conteúdos, porque nem todos os alunos são gênios, alguns são lentos } \\
\text { e tem muita dificuldade de aprender, assim como eu. }\end{array}$ \\
\hline Estudante 13 & Mais exemplos e explicações detalhadas. \\
\hline
\end{tabular}

\section{Quadro 1. Recomendações para melhorar a compreensão.}

Foi questionado se o IFRN possui laboratório de informática para acesso em horário diferente das aulas; $96 \%$ dos estudantes afirmaram que sim e 4\% que não. Procurou-se averiguar se os computadores dos laboratórios de informática possuem softwares necessários para realizar as atividades de programação e $96 \%$ dos estudantes responderam que sim, os outros $4 \%$ afirmaram que não.

Perguntamos se a instituição possui biblioteca e os alunos foram unânimes ao responderem que sim. Por outro lado, na indagação se na biblioteca existem livros suficientes para todos os estudantes, $84 \%$ afirmam que existe e $16 \%$ que não existem. Ainda foi questionado se os livros de programação disponibilizados na biblioteca são atuais, $76 \%$ afirmaram que sim e $24 \%$ que não. 


\section{Conclusão}

Neste trabalho objetivou-se conhecer a realidade dos estudantes do curso de ADS do IFRN, Campus Pau dos Ferros, em relação às dificuldades encontradas nas disciplinas de programação. Diante do exposto, percebe-se que os estudantes possuem distintas problemáticas que acabam comprometendo sua aprendizagem, onde uma delas é a dificuldade em colocar em prática a parte teórica que foi estudada.

Além disso, verificou-se que os discentes dedicam pouco tempo na realização de atividades relacionadas à programação, possuem problemas na abstração do problema $\mathrm{e}$ na questão de raciocínio lógico, e um número considerável de estudantes, quando não conseguem sucesso em resolver essas tarefas, buscam resoluções na internet, isso pode fazer com que os estudantes não pratiquem e não desenvolvam a lógica de programação.

Portanto, todos esses problemas podem fazer com que o estudante se sinta desmotivado, culminando na reprovação, trancamento de disciplinas e até mesmo na desistência/abandono do curso. Em relação aos trabalhos futuros, pretende-se investigar a visão deles frente às dificuldades de aprendizagem apresentadas pelos estudantes e propor possíveis soluções.

\section{Referências}

Bosse, Y.; Gerosa, M. A. (2015) "Reprovações e trancamentos nas disciplinas de introdução à programação da Universidade de São Paulo: um estudo preliminar”. In: XXIII Workshop sobre Educação em Computação, 2015, Recife/PE. Anais [...]. Recife/PE, 2015, 10 p.

Bosse, Yorah. (2020) Padrões de dificuldades relacionadas com o aprendizado de programação. 2020. Tese de Doutorado. Universidade de São Paulo.

Gil, A. C. (2018) Como Elaborar projetos de pesquisa. 6.ed. São Paulo: Atlas.

Gomes, A.; Henriques, J.; Mendes, A. J. (2008). Uma proposta para ajudar alunos com dificuldades na aprendizagem inicial de programação de computadores. Educação, Formação \& Tecnologias, v.1, n. 1, p. 93-103.

Medeiros, Rodrigo Pessoa. (2019) Hello, world: uma análise sobre dificuldades no ensino e na aprendizagem de introdução à programação nas universidades.

Santos, R. P. D.; Costa, H. A. X. (2006) Análise de Metodologias e Ambientes de Ensino para Algoritmos, Estruturas de Dados e Programação aos iniciantes em Computação e Informática. INFOCOMP JOURNAL OF COMPUTER SCIENCE, v. 5, n. 1, p. 41-50.

Vieira, C. E. C.; Junior, J. A. T. D.L.; Vieira, P. D. P. (2015) Dificuldades no Processo de Aprendizagem de Algoritmos: uma Análise dos Resultados na Disciplina de AL1 do Curso de Sistemas de Informação da FAETERJCampus Paracambi. Cadernos UniFOA, v. 10, n. 27, p. 5-15.

Zanella, L. C. H. (2013) Metodologia de pesquisa. 2. ed. Florianópolis: Departamento de Ciências da Administração/UFSC. 